\title{
ADAPTABILIDADE DE DIFERENTES CULTIVARES DE MILHO SUBMETIDAS ÀS CONDIÇÕES CLIMÁTICAS DO NORDESTE DO PARÁ
}

\author{
Camila Sampaio Leal Patez Alves'; Vinicius Masala Amaral2; Leticia Bezerra Cuzzuol3; Núbia de Fátima Alves \\ Santos ; Márcio Roberto da Silva Melo ${ }^{5}$; Vitor Quintela de Souza ${ }^{6}$; Sannah Mohamad Birani ; Luciana da Silva \\ Borges $^{8}$. \\ 1Universidade Federal Rural da Amazônia (UFRA), Paragominas, Pará, Brasil, camilealpatez@gmail.com \\ 2UFRA, Paragominas, Pará, Brasil, vinicius.masala@hotmail.com \\ 3UFRA, Paragominas, Pará, Brasil, leticiacuzzuol@gmail.com \\ 4UFRA, Paragominas, Pará, Brasil, nubia.santos@ufra.edu.br \\ 5UFRA, Paragominas, Pará, Brasil, marcio.melo@ufra.edu.br \\ ${ }^{6}$ Instituto de Terras do Pará (ITERPA), Belém, Pará, Brasil, quintelav@gmail.com \\ 7UFRA, Paragominas, Pará, Brasil, sannahmb@gmail.com \\ 8UFRA, Paragominas, Pará, Brasil, luciana.borges@ufra.edu.br
}

RESUMO: Este trabalho teve como objetivo avaliar o desempenho e adaptabilidade de diferentes cultivares de milho, comerciais e não comerciais submetidos às condições climáticas de Dom Eliseu, no nordeste do Pará. O experimento foi executado na Fazenda Flor do Ipê, localizada no município de Dom Eliseu, no km 22 da Rodovia BR-222, com coordenada geográfica $4^{\circ} 17^{\prime} 30.93^{\prime \prime} S$ e 47²4 $38.54^{\prime \prime} \mathrm{O}$. O clima é caracterizado como do tipo Awi da classificação de Köppen, isto é, clima tropical chuvoso com estação seca bem definida. Foram registradas Temperatura do ar $\left({ }^{\circ} \mathrm{C}\right)$ e Precipitação Pluviométrica $(\mathrm{mm})$ através da estação meteorológica pertencente à APROSOJA - Associação dos Produtores de Soja do Brasil. O experimento foi realizado em delineamento inteiramente ao acaso, com 12 cultivares de milho (Zea mays L.), sendo 6 comerciais e 6 não comerciais, com cinco repetições em cada cultivar. Foi utilizado o Software Sisvar para análise de variância, com comparação de médias através do Teste de Tukey a 5\% de probabilidade. A temperatura do ar, nos diferentes meses do período experimental, se manteve em níveis toleráveis para o cultivo de milho. A cultivar não comercial que melhor se adaptou ao ambiente de Dom Eliseu foi a DOWCOD030PW. Para as cultivares comerciais a melhor adaptação às condições edafoclimáticas foi apresentada pela 2B587PW.

PALAVRAS-CHAVE: Adaptação, Características agronômicas, Produtividade.

\section{ADAPTABILITY OF DIFFERENT MAIZE CULTIVARS SUBMITTED TO THE CLIMATIC CONDITIONS OF NORTHEAST OF PARÁ STATE}

\begin{abstract}
The objective of this experiment was to evaluate the performance and adaptability of different commercial and non-commercial maize cultivars submitted to Dom Eliseu, Pará climatic conditions. The experiment was carried out at Flor do Ipê Farm, located in the municipality of Dom Eliseu, at km 22 of Highway BR-222, with geographic coordinate $4^{\circ} 17 ' 30.93$ "S and $47^{\circ} 48^{\prime} 38.54^{\prime \prime} \mathrm{W}$. The climate is characterized as Awi-type Köppen classification, ie rainy tropical climate with well-defined dry season. Air temperature $\left({ }^{\circ} \mathrm{C}\right)$ and
\end{abstract}


rainfall $(\mathrm{mm})$ were recorded through meteorological station belonging to APROSOJA Brazilian Soybean Producers Association. The experiment was carried out in a completely randomized design with 12 cultivars of maize (Zea mays L.), 6 commercial and 6 noncommercial, with five replicates in each cultivar. The Sisvar Software was used for analysis of variance, with means comparison using the Tukey Test at 5\% probability. The air temperature in the different months of the experimental period remained at tolerable levels for maize cultivation. The non-commercial cultivar that best adapted to Dom Eliseu's environment was DOWCOD030PW. For commercial cultivars the best adaptation to soil and climatic conditions was presented by 2B587PW.

KEYWORDS: Adaptation, Agronomic characteristics, Productivity.

\section{ADAPTABILIDAD DE DIFERENTES CULTIVARES DE MAÍIZ SOMETIDAS A LAS CONDICIONES CLIMÁTICAS EN EL NORESTE DEL ESTADO DE PARÁ}

RESUMEN: Este trabajo tuvo como objetivo evaluar el desempeño y adaptabilidad de diferentes cultivares de maíz, comerciales y no comerciales sometidos a las condiciones climáticas de Don Eliseo, Pará. El experimento fue ejecutado en la Hacienda Flor do Ipê, ubicada en el municipio de Dom Eliseu, en el km 22 de la Ruta BR-222, con coordenada geográfica $4^{\circ} 17^{\prime} 30.93$ "S y $47^{\circ} 48^{\prime} 38.54^{\prime \prime}$ O. El clima se caracteriza como el tipo Awi de la clasificación de Köppen, es decir, clima tropical lluvioso con estación seca bien definida. Se registraron Temperatura del aire $\left({ }^{\circ} \mathrm{C}\right)$ y Precipitación Pluviométrica $(\mathrm{mm})$ a través de la estacione meteorológica perteneciente a APROSOJA - Asociación de Productores de Soja de Brasil. El experimento fue realizado en delineamiento enteramente al azar, con 12 cultivares de maíz (Zea mays L.), siendo 6 comerciales y 6 no comerciales, con cinco repeticiones en cada cultivar. Se utilizó el software Sisvar para análisis de varianza, con comparación de promedios a través del test de Tukey al 5\% de probabilidad. La temperatura del aire, en los diferentes meses del período experimental, se mantuvo en niveles tolerables para el cultivo de maíz. La cultivar no comercial que mejor se adaptó al ambiente de Don Eliseo fue la DOWCOD030PW. Para las cultivares comerciales la mejor adaptación a las condiciones edafoclimáticas fue presentada por la 2B587PW.

PALABRAS CLAVE: Adaptación, Características agronómicas, Productividad.

\section{INTRODUÇÃO}

O milho (Zea mays L.) é uma planta

que se originou na América Central, é cultivado em todo o Brasil, apresenta grande potencial econômico, devido às diversas formas de sua utilização, desde a alimentação humana e animal 
até a indústria de alta tecnologia e utilização na produção de biocombustíveis (BARAVIERA et al., 2014).

No Brasil o cultivo do milho é muito expressivo, estando presente em praticamente todo o território, ocupando o terceiro lugar na produção de milho do mundo com uma produção de 67 milhões de toneladas na safra 2015/2016, sendo o segundo grão mais cultivado no território brasileiro com representatividade de 23\%. As regiões Sul, Sudeste e CentroOeste respondem por cerca de $80 \%$ da produção nacional de milho e concentram as maiores produtividades da cultura no país (CONAB, 2016).

O Estado do Mato Grosso está em primeiro lugar na produção de milho do Brasil, produzindo um total de 20 milhões de toneladas e representando 24\% da produção nacional na safra 15/16 (CONAB, 2016).

Encontram-se no mercado, híbridos de milho com diferentes características fisiológicas que se adaptam melhor às condições de ambiente de diferentes regiões e que visam a atender as finalidades do agricultor (NASCIMENTO et al., 2011).

De acordo com Nascimento et al. (2011), para atender às características peculiares e diversificadas das várias regiões produtoras do Brasil, foram desenvolvidos novos sistemas de produção e, para tanto, os melhoristas empenharam-se em obter híbridos de menor porte, precoces e mais eficientes na absorção de água, luz, temperatura e absorção de nutrientes. Tais características permitiram aperfeiçoar a utilização de germoplasmas de cultivares de milho de clima temperado nos mais diversos climas encontrados no território brasileiro (SZCESNY, 2015).

O uso de cultivares adaptadas às condições edafoclimáticas para cada região de cultivo é fator essencial para que o produtor obtenha altas produtividades no desenvolvimento da atividade agrícola (HANASHIRO et al., 2013).

Portanto, o presente trabalho teve como objetivo avaliar o desempenho e 
adaptabilidade de diferentes cultivares de milho submetidos às condições climáticas do nordeste do Pará.

\section{MATERIAL E MÉTODOS}

O experimento foi executado na Fazenda Flor do Ipê, localizada no nordeste do estado do Pará no município de Dom Eliseu, no km 22 da Rodovia BR-222, com coordenadas geográficas 4¹7'30.93"S

e $47^{\circ} 48^{\prime} 38.54^{\prime \prime} \mathrm{O}$.

O clima da área é representado pelo tipo climático Awi da classificação de Koppen (clima tropical chuvoso, com expressivo período de estiagem). A temperatura média anual é $26^{\circ} \mathrm{C}$, e as médias das máximas e mínimas, respectivamente, em torno de $33^{\circ} \mathrm{C}$ e $22{ }^{\circ} \mathrm{C}$. A média anual da umidade relativa do ar é de $80 \%$. O total pluviométrico anual é de aproximadamente 1740 milímetros, com o período mais chuvoso estendendo-se de janeiro a maio. O período menos chuvoso ocorre de julho a novembro, resultando em expressivos déficits de água no solo para as plantas (GONÇALVES et al., 2008).

A propriedade exerce atividades como: pecuária de corte, silvicultura, piscicultura e agricultura, esta última sendo a principal atividade executada na área. Possui alta tecnificação no manejo da agricultura, trabalhando com o cultivo de soja e milho, obedecendo ao regime chuvoso da região.

Foram registradas Temperatura do ar $\left({ }^{\circ} \mathrm{C}\right)$ e Precipitação Pluviométrica $(\mathrm{mm})$ através das estações meteorológicas pertencentes à APROSOJA - Associação dos Produtores de Soja do Brasil, localizada em Dom Eliseu, Pará, que foram disponibilizadas pelo proprietário da fazenda onde foi realizado o experimento (Figura 1). Os dados meteorológicos são dos meses de janeiro (plantio) até junho (colheita). A temperatura do ar, nos diferentes meses do período experimental, se apresentou em níveis toleráveis para o cultivo de milho cuja temperatura ótima é entre $25{ }^{\circ} \mathrm{C}$ a $30{ }^{\circ} \mathrm{C}$, 
dependendo do estádio de o cultivo é de $30{ }^{\circ} \mathrm{C}$, chamada desenvolvimento em que a planta se temperatura limite superior (SOUZA, encontra. A temperatura máxima para 1989).

Figura 1. Dados de Temperatura do ar $\left({ }^{\circ} \mathrm{C}\right)$ e Precipitação Pluviométrica $(\mathrm{mm})$ na fazenda experimental no período da safra 15/16.

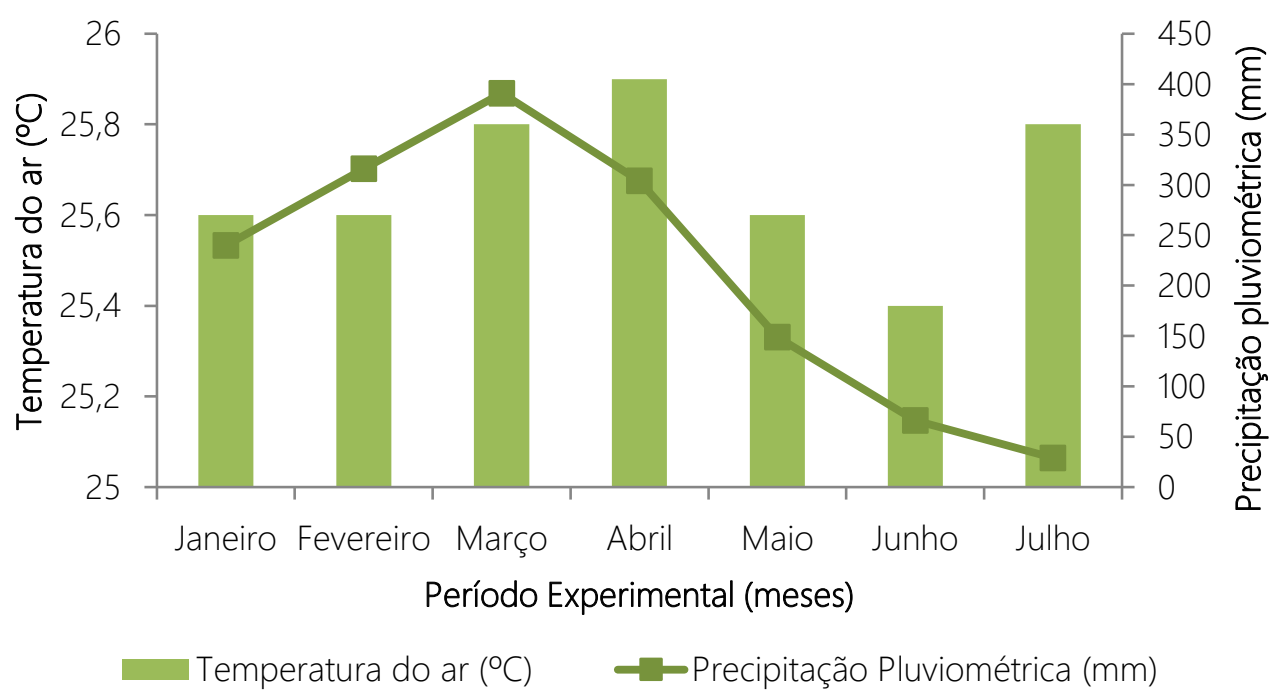

O solo do local experimental é hectare, posteriormente seguiu o classificado como Latossolo Amarelo plantio.

distrófico. Realizou-se o preparo

As sementes foram disponibilizadas iniciando pela gradagem, seguindo da pela empresa Dow Agrosciences, que aplicação de calcário, seguindo estavam devidamente embaladas em recomendações agronômicas e o pacotes de papel. Antes do plantio a manejo empregado pela propriedade, plantadeira mecânica passou posteriormente dessecação para a distribuindo o adubo e abrindo as retirada da vegetação indesejada. Foi linhas de plantio. Foi realizado plantio realizada adubação de fundação antes manual com auxílio de matracas com do plantio, com aplicação de 350 kg de MAP (10\% de $\mathrm{N}$ e 46 de $\left.\mathrm{P}_{2} \mathrm{O}_{5}\right)$ por distribuição de duas sementes por cova. Foram utilizadas 6 cultivares de 
milho comerciais (C.C) e 6 cultivares de milho não comerciais (N.C), onde cada cultivar constituiu uma parcela formada de $3 \times 8$ metros, sendo esta composta por 5 linhas de 8 metros de comprimento/linha, com espaçamento de $33 \mathrm{~cm}$ entre plantas e $50 \mathrm{~cm}$ entre linhas. Cada linha representava uma repetição, no total de 5 por cultivar.

O desbaste foi realizado no estádio V4, selecionando a planta com melhores características, como, vigor, sanidade e porte, a outra planta foi descartada.

Foram realizadas as seguintes avaliações: germinação e vigor inicial, stand inicial, altura de planta e altura de espiga, stand final, colheita, empalhamento de espiga, grãos ardidos, umidade dos grãos, massa de mil grãos (MMG) e produtividade.

A germinação e vigor inicial são avaliações qualitativas da uniformidade de emergência das plântulas na parcela, para avaliação foi utilizada escala com notas de 1 (ruim) a 9 (excelente), levando-se em consideração o número de falhas, excluindo-se a bordadura. Estas análises foram realizadas na fase V4, antes do desbaste. O stand inicial foi avaliado, após o desbaste, através da contagem de plantas por linha, com o intuito de observar também o potencial germinativo das sementes.

A altura da planta foi mensurada através do comprimento, a partir da altura do solo até a inserção da folha bandeira de uma planta representativa de cada linha em cada parcela, sendo amostrada ao centro da linha (fora da bordadura). Já a altura de espiga foi avaliada pela medida do solo até a inserção da espiga, também, de uma planta representativa de cada linha em cada parcela.

Todas as medidas foram realizadas com auxílio de fita métrica. $\bigcirc$ stand final foi avaliado por meio da contagem do número de plantas, no momento da colheita, nas duas linhas centrais da parcela.

A colheita foi realizada manualmente de 2 linhas centrais com 8 metros de comprimento em cada parcela. A avaliação do empalhamento 
foi avaliado após a colheita, utilizando a escala de 1 (Ruim) a 9 (Bom), onde a nota 1 - 2: Palha sem pressão e grãos expostos (Ruim); Nota 3 - 4: Expõe os grãos da ponta do sabugo (Regular); Nota 5 - 6: Expõe a ponta do sabugo (Bom); Nota 7 - 8: Não expõe os grãos, mas a palha é parcialmente fechada na ponta (Ótimo); Nota 9: Não expõe os grãos e a palha é fechada na ponta (Excelente), Após a colheita as espigas foram colocadas em sacos de estopa e encaminhadas para debulha, que foi feita de forma manual.

Também foi avaliada a ocorrência de podridão de grãos (grãos ardidos), onde separou-se amostras de $100 \mathrm{~g}$ de grãos de cada parcela, que foram levadas ao laboratório de classificação de grãos. Os grãos foram separados e identificados, os grãos considerados ardidos foram pesados e descritos em porcentagem. A umidade dos grãos foi realizada com auxílio do medidor de umidade tipo caneca modelo mini GAC.

A massa de mil grãos (MMG) foi realizado com a contagem de mil grãos de milho e posterior pesagem dos mesmos em balança eletrônica de precisão. Para avaliar a produtividade, foi pesada a massa de todos os grãos colhidos em cada parcela em balança eletrônica de precisão. Após a pesagem, foi realizada a estimativa de produtividade para um hectare.

Foi utilizado o Software Sisvar para análise de variância, com comparação de médias através do Teste de Tukey a 5\% de probabilidade.

\section{RESULTADOS E DISCUSSÃO}

Na Tabela 1 estão os resultados obtidos para as variáveis agronômicas germinação (em nota), Stand inicial (média de plantas por parcela) e vigor das plantas (em nota). 
Tabela 1. Variáveis agronômicas (germinação, stand inicial e vigor) de cultivares comerciais e não comerciais de milho em Dom Eliseu -PA.

\begin{tabular}{|c|c|c|c|}
\hline Cultivar & $\begin{array}{c}\text { Germinação } \\
\text { (nota) }\end{array}$ & $\begin{array}{l}\text { Vigor } \\
\text { (nota) }\end{array}$ & $\begin{array}{l}\text { Stand Inicial } \\
\text { (plantas) }\end{array}$ \\
\hline \multicolumn{4}{|c|}{ Não comerciais } \\
\hline DOWCOD035PW & $8,00^{b}$ & $9,00^{a}$ & $24,20^{b c}$ \\
\hline DOWCOD032PW & $8,00^{\mathrm{b}}$ & $8,00^{b}$ & $23,60^{\mathrm{bcd}}$ \\
\hline & $9,00^{\mathrm{a}}$ & $9,00^{\mathrm{a}}$ & $28,00^{a}$ \\
\hline DOWCOD030PW & $7,00^{c}$ & $8,00^{b}$ & $20,60^{\text {de }}$ \\
\hline DOWCOD036PW & $8,00^{b}$ & $8,00^{b}$ & $21,80^{\text {cde }}$ \\
\hline $\begin{array}{l}\text { DOWCOD054PW } \\
\text { DOWCOD034PW }\end{array}$ & $8,00^{\mathrm{b}}$ & $9,00^{\mathrm{a}}$ & $22,80^{\text {bcde }}$ \\
\hline \multicolumn{4}{|c|}{ Comerciais } \\
\hline 2B512PW & $9,00^{a}$ & $9,00^{a}$ & $26,20^{a b}$ \\
\hline M580PW & $8,00^{\mathrm{b}}$ & $8,00^{b}$ & $21,20^{\text {cde }}$ \\
\hline M699PW & $7,00^{c}$ & $8,00^{b}$ & $20,00^{e}$ \\
\hline CD3612PW & $8,00^{b}$ & $8,00^{b}$ & $22,80^{\text {bcde }}$ \\
\hline 2B587PW & $8,00^{\mathrm{b}}$ & $9,00^{a}$ & $23,40^{\text {bcde }}$ \\
\hline 2B810PW & $8,00^{\mathrm{b}}$ & $9,00^{a}$ & $20,60^{\text {de }}$ \\
\hline $\mathrm{QMt}$ & 1,81 & 1,36 & 28,37 \\
\hline
\end{tabular}

Médias seguidas de letras minúsculas distintas, na mesma coluna são diferentes $(P<0,05)$.

Para a variável agronômica germinação pôde-se observar que a cultivar N.C que apresentou melhor desempenho foi a DOWCOD030PW, que obteve nota 9,0, caracterizando uma cultivar com boa capacidade de germinação, isto se deve pelo fato desta cultivar apresentar melhor adaptabilidade, pois a fase de emergência é o momento onde se necessita de condições ambientais favoráveis no local onde foram semeadas (SIMONI et al., 2011).
Nas cultivares comerciais, atentase para os resultados obtidos pela cultivar M699PW, que diferiu estatisticamente das demais, pois obteve nota 7,0, o que pode ser explicado pela não adaptação desta cultivar às condições da região. O efeito desta manifestação tem sido estudado em todas as regiões do país, tanto para os diversos tipos de cultivares existentes no mercado, corno para vários tipos de linhagens obtidos 
na cultura do milho (ARIAS, 1996; RIBEIRO et al., 2000).

Quanto ao Vigor, pôde-se observar que todas as cultivares apresentaram bom desempenho, diferindo estatisticamente, porém, todas dentro do recomendado, que é uma nota acima de 8. Deve-se atentar para a variável vigor de sementes, pois a qualidade fisiológica das sementes é caracterizada pela germinação e vigor (SOUZA et al., 2005), sendo que o vigor pode ser definido como a soma de atributos que conferem à semente o potencial para germinar, emergir e resultar rapidamente em plântulas normais, em ampla diversidade de condições ambientais (MARCOS FILHO, 2005).

Para a variável stand inicial, quando comparadas as cultivares entre si, a que apresentou maior número de plantas por parcela foi a cultivar N.C DOWCOD030PW, com média de 28,00 plantas/parcela, caracterizando uma cultivar com alta adaptabilidade e com melhor desempenho em relação ao crescimento inicial, esta característica tem grande importância, pois o crescimento inicial tem grande relevância no prosseguimento da lavoura de milho, pois o stand afeta a arquitetura das plantas, altera $\mathrm{O}$ crescimento e o desenvolvimento, e influencia na produção e partição de foto assimilados (SOUZA et al., 2005).

Para a variável agronômica altura de plantas e altura de espiga (Tabela 2), observou-se que a cultivar comercial CD3612PW obteve maior porte em relação às demais cultivares, com média de 2,93 m, vale ressaltar que todas as cultivares foram plantadas com mesmo espaçamento, e isto pode ter influenciado no maior crescimento da cultivar em questão, pois quando submetida a um espaçamento inadequado para seu desenvolvimento normal, as plantas apresentam tendência natural de aumento de sua altura (ARGENTA; SILVA; SANGOI, 2001; ALVAREZ; PINHO; BORGES, 2006), a mesma cultivar também apresentou maior altura de espiga, apresentando $1,51 \mathrm{~m}$. Isto pode ser explicado também, em razão do efeito 
combinado da competição consequente estímulo da dominância intraespecífica por luz, em situações de apical das plantas (SANGOl et al., cultivos com alta densidade, e 2002).

Tabela 2. Variáveis agronômicas (Altura de planta, Altura de Espiga e Empalhamento) de cultivares, comerciais e não comerciais de milho em Dom Eliseu -PA.

\begin{tabular}{cccc}
\hline Cultivar & Altura de planta $(\mathrm{m})$ & Altura da espiga $(\mathrm{m})$ & $\begin{array}{c}\text { Empalhamento } \\
\text { (nota) }\end{array}$ \\
\hline \multicolumn{5}{c}{ Não comerciais } \\
\hline DOWCOD035PW & $2,01^{\mathrm{g}}$ & $1,21^{\mathrm{e}}$ & $8,00^{\mathrm{b}}$ \\
DOWCOD032PW & $1,91^{\mathrm{h}}$ & $1,15^{\mathrm{g}}$ & $8,00^{\mathrm{b}}$ \\
DOWCOD030PW & $2,80^{\mathrm{b}}$ & $1,3^{\mathrm{b}}$ & $9,00^{\mathrm{a}}$ \\
DOWCOD036PW & $2,68^{\mathrm{c}}$ & $1,27^{\mathrm{d}}$ & $8,00^{\mathrm{b}}$ \\
DOWCOD054PW & $2,42^{\mathrm{f}}$ & $1,35^{\mathrm{b}}$ & $8,00^{\mathrm{b}}$ \\
DOWCOD034PW & $2,55^{\mathrm{d}}$ & $1,31^{\mathrm{c}}$ & $9,00^{\mathrm{a}}$ \\
\hline \multicolumn{4}{c}{ Comerciais } \\
\hline 2B512PW & $2,50^{\mathrm{e}}$ & $1,18^{\mathrm{f}}$ & $8,00^{\mathrm{b}}$ \\
M580PW & $2,40^{\mathrm{f}}$ & $1,03^{\mathrm{i}}$ & $8,00^{\mathrm{b}}$ \\
M699PW & $2,55^{\mathrm{d}}$ & $1,15^{\mathrm{g}}$ & $9,00^{\mathrm{a}}$ \\
CD3612PW & $2,93^{\mathrm{a}}$ & $1,51^{\mathrm{a}}$ & $8,00^{\mathrm{b}}$ \\
2B587PW & $2,54^{\mathrm{d}}$ & $1,17^{\mathrm{fg}}$ & $8,00^{\mathrm{b}}$ \\
2B810PW & $2,50^{\mathrm{e}}$ & $1,08^{\mathrm{h}}$ & $8,00^{\mathrm{b}}$ \\
\hline QMt & 0,41 & 0,09 & 1,02 \\
\hline
\end{tabular}

Médias seguidas de letras minúsculas distintas, na mesma coluna são diferentes $(P<0,05)$.

Já a cultivar N.C. DOWCOD032PW foi a que apresentou menor porte de planta, com 1,91m, diferindo estatisticamente das demais cultivares experimentais, uma vez que a cultivar conseguiu adaptar-se melhor ao número de plantas na parcela, esta cultivar também apresentou a menor altura de espiga, com 1,15 m. Plantas e espigas de menor altura tem sido um caractere de interesse entre os produtores de milho por permitir cultivos em maiores densidades populacionais e maior eficiência na colheita mecânica como também reduz problemas associados ao acamamento e quebramento de plantas antes do ponto de colheita, comumente apresentado por plantas de porte alto (ALMEIDA et al., 2000). 
Para a variável Empalhamento, a C.C que obteve melhor nota foi M699PW, e a N.C foi a DOWCOD030PW, ambas com nota 9,0. O bom empalhamento se torna uma característica desejável, pois segundo Lorini (2005) é necessário que a cultivar apresente bom empalhamento com cobertura adequada na ponta da espiga, evitando danos causados por insetos e fungos no campo e em condições de armazenamento. Um empalhamento indesejado propicia a ocorrência de grãos ardidos, com maior teor de ácidos fenólicos e, consequentemente, grãos mais susceptíveis às pragas e doenças.

Na Tabela 3 estão os resultados das variáveis agronômicas Umidade dos Grãos, Grãos Ardidos e Massa de Mil Grãos (MMG). Para a variável umidade dos grãos (\%), pode-se observar que as cultivares N.C DOWCOD030PW e DOWCOD036PW apresentaram maior teor de umidade dos grãos com 24.2 e 24.5\% respectivamente, valores que ultrapassam os adequados, segundo a Embrapa Milho e Sorgo (2011) a umidade adequada para colheita de milho está entre 13 e 20\%, quando este valor exceder será necessária a secagem dos grãos até que se atinja a umidade adequada para o armazenamento a qual demanda custo para o produtor, sendo interessantes grãos que apresentem maior uniformidade de umidade no momento da colheita.

Em relação aos grãos ardidos, observou-se que nenhuma das cultivares avaliadas apresentou níveis de grãos ardidos superior ao limite de 6\%, segundo MAPA (2011) em regulamentação atualizada, grãos de milho ardidos são grãos ou pedaços de grãos de milho que perderam a cor característica, por ação do calor e umidade ou por fermentação, em qualquer parte do grão e que se tolera a presença de $6 \%$ de grãos com esta característica. No presente trabalho, a maior quantidade de grãos ardidos foi observada para a cultivar não 
comercial DOWCOD036PW, com empalhadas apresentam menores 5.50\%. Estes resultados foram níveis de grãos ardidos, onde a palha influenciados pelos resultados obtidos protege os grãos dificultando a entrada na variável Empalhamento das espigas, de água e organismos infecciosos pois é reconhecido que espigas bem (STEFANELLO et al., 2012).

Tabela 3. Variáveis agronômicas, Umidade dos grãos, Grãos ardidos e Massa de Mil Grãos (MMG), de cultivares comerciais e não comerciais de milho, em Dom Eliseu -PA.

\begin{tabular}{cccc}
\hline Cultivar & $\begin{array}{c}\text { Umidade dos grãos } \\
(\%)\end{array}$ & Grãos ardidos (\%) & MMG (g) \\
\hline DOWCOD035PW & $21,40^{\mathrm{b}}$ & Não comerciais \\
DOWCOD032PW & $19,10^{\mathrm{b}}$ & $3,70^{\mathrm{d}}$ & $360,00^{\mathrm{h}}$ \\
DOWCOD030PW & $24,20^{\mathrm{a}}$ & $1,00^{\mathrm{j}}$ & $389,00^{\mathrm{e}}$ \\
DOWCOD036PW & $24,50^{\mathrm{a}}$ & $5,00^{\mathrm{c}}$ & $391,00^{\mathrm{c}}$ \\
DOWCOD054PW & $20,50^{\mathrm{b}}$ & $5,50^{\mathrm{a}}$ & $337,00^{\mathrm{i}}$ \\
DOWCOD034PW & $21,50^{\mathrm{b}}$ & $5,20^{\mathrm{b}}$ & $390,00^{\mathrm{d}}$ \\
\hline & $3,00^{\mathrm{e}}$ & $458,00^{\mathrm{a}}$ \\
\hline 2B512PW & Comerciais & $380,00^{\mathrm{g}}$ \\
M580PW & $20,80^{\mathrm{b}}$ & $340,00^{\mathrm{i}}$ \\
M699PW & $24,70^{\mathrm{a}}$ & $1,00^{\mathrm{j}}$ & $412,00^{\mathrm{b}}$ \\
CD3612PW & $23,90^{\mathrm{a}}$ & $2,00^{\mathrm{g}}$ & $381,00^{\mathrm{f}}$ \\
2B587PW & $17,80^{\mathrm{c}}$ & $1,00^{\mathrm{j}}$ & $280,00^{\mathrm{j}}$ \\
2B810PW & $25,10^{\mathrm{a}}$ & $1,50^{\mathrm{i}}$ & $278,00^{\mathrm{k}}$ \\
\hline QMt & $24,30^{\mathrm{a}}$ & $1,80^{\mathrm{h}}$ & 373,93 \\
\hline
\end{tabular}

Médias seguidas de letras minúsculas distintas, na mesma coluna são diferentes $(P<0,05)$.

Para a variável Massa de Mil Grãos (MMG), a C.C que se destacou foi a M699PW que apresentou melhor desempenho, com 412 gramas, diferindo de trabalho realizado por Assunção e Frasson (2014), em Mato Grosso, que encontrou MMG para a cultivar citada de 341, 95 gramas.
A cultivar comercial 2B810PW foi a que se apresentou as menores médias de MMG, com 278 gramas, Cruz (2010) em trabalho executado em Sete Lagoas $M G$, encontraram resultados semelhantes ao desta pesquisa, onde a cultivar apresentou média de 280 gramas. 
A variável stand final (Tabela 4) é a média do número de plantas das linhas de colheita para cada parcela, para esta variável pôde-se observar que a cultivar N.C DOWCOD030PW e a CC 2B512PW obtiveram as maiores médias, com 25 plantas/parcela útil. Esta cultivar havia apresentado stand inicial de 28 plantas por parcela, sendo o melhor desempenho, devendo se atentar para a produtividade da mesma, pois Araújo (2013) constatou variação no stand final de cultivares de milho, prejudicando a produtividade de grãos.

Tabela 4. Variáveis agronômicas, Stand Final e Produtividade em hectare (estimativa), de cultivares comerciais e não comerciais de milho em Dom Eliseu -PA.

\begin{tabular}{ccc}
\hline Cultivar & $\begin{array}{c}\text { Stand Final } \\
\text { (nas linhas de colheita) }\end{array}$ & $\begin{array}{c}\text { Produtividade } \\
(\mathrm{kg} / \mathrm{ha})\end{array}$ \\
\hline NOWCOD035PW & $23^{\mathrm{b}}$ comerciais & $7.071^{\mathrm{b}}$ \\
DOWCOD032PW & $23^{\mathrm{b}}$ & $7.554^{\mathrm{b}}$ \\
DOWCOD030PW & $25^{\mathrm{a}}$ & $7.948^{\mathrm{b}}$ \\
DOWCOD036PW & $19^{\mathrm{d}}$ & $5.047^{\mathrm{c}}$ \\
DOWCOD054PW & $18^{\mathrm{e}}$ & $5.047^{\mathrm{c}}$ \\
DOWCOD034PW & $24^{\mathrm{b}}$ & $7.582^{\mathrm{a}}$ \\
\hline & Comerciais & \\
\hline 2B512PW & $25^{\mathrm{a}}$ & $7.650^{\mathrm{b}}$ \\
M580PW & $20^{\mathrm{d}}$ & $6.126^{\mathrm{c}}$ \\
M699PW & $19^{\mathrm{d}}$ & $6.119^{c}$ \\
CD3612PW & $21^{\mathrm{c}}$ & $8.391^{\mathrm{a}}$ \\
2B587PW & $23^{\mathrm{b}}$ & $7.593^{\mathrm{b}}$ \\
2B810PW & $21^{\mathrm{c}}$ & $7.125^{\mathrm{b}}$ \\
\hline QMt & 0,76 & 3,51 \\
\hline
\end{tabular}

Médias seguidas de letras minúsculas distintas, na mesma coluna são diferentes $(P<0,05)$.

Dentre as cultivares comerciais a que mais se destacou foi a 2B512PW, apresentando média de 25 plantas/parcela obtendo uma variação muito pequena comparadas ao stand inicial, pois possuía 26,20 plantas/parcela resultados que corroboram com os encontrados por 
Freitas et. al (2013) com trabalho realizado em São Paulo, onde utilizando a mesma cultivar, obtiveram média de stand final de 25,1 plantas/parcela.

Em relação à variável produtividade, para as cultivares C.C, pode-se observar a maior produtividade para a cultivar CD3612PW, com 8.391 kg/ha, resultados semelhantes aos encontrados por Cardoso (2014) em trabalho realizado no leste maranhense, onde a mesma cultivar apresentou 7.250 kg/ha. A cultivar não comercial DOWCOD030PW apresentou produtividade de 7.948 kg/ha, o que a torna promissora para lançamentos nas próximas safras, embora ainda seja necessária realização de mais testes a campo.

Quanto às N.C, DOWCOD036PW e DOWCOD054PW, ambas apresentaram mesmo resultado, com $5.047 \mathrm{~kg} / \mathrm{ha}$, sendo o pior desempenho entre as cultivares, resultado explicado

\section{REFERÊNCIAS}

ALMEIDA, M. L.; MEROTTO JUNIOR, A.; SANGOI, L.; ENDER, M.; GUIDOLIN, A. pela questão adaptativa das cultivares, pois o ambiente se encontrava dentro do recomendado para o cultivo de milho, porém segundo Silva (2011) existem cultivares desenvolvidas para regiões com menores disponibilidades hídricas, consequentemente produzem menos em regiões muito chuvosas e mais em localidades menos chuvosas.

\section{CONCLUSÃO}

Com base nos resultados, pôde-se concluir que para as cultivares comerciais a melhor adaptação às condições climáticas foi apresentada pela CD3612PW. A cultivar não comercial que melhor se adaptou ao ambiente de Dom Eliseu foi a DOWCOD030PW. Estas cultivares apresentaram em todas as variáveis, bom desempenho agronômico e resultados produtivos elevados, favorecendo o melhor posicionamento das mesmas para as condições do nordeste do Pará.

F. Incremento na densidade de plantas: uma alternativa para aumentar o rendimento de grãos de milho em regiões de curta estação estival de 
crescimento. Ciência Rural, Santa Maria, Porto Alegre, RS, v. 30, n. 1, p. 23-29, 2000.

ALVAREZ, C. G. D.; PINHO, R. G.; BORGES, I. D. Avaliação de características agronômicas e de produção de forragens e grãos de milho em diferentes densidades de semeadura e espaçamentos entre linhas. Ciência e Agrotecnologia, v.30, p. 402-408, 2006.

ARAÚJO, A. V.; BRANDÃO JUNIOR, D. S.; FERREIRA, I. C. P. V.; COSTA, C. A. PORTO, B. B. A. Desempenho agronômico de variedades crioulas e híbridos de milho cultivados em diferentes sistemas de manejo. Revista Ciência Agronômica, v. 44, p. 885-892, 2013.

ARGENTA， G. S.; SILVA, P. R. F.; SANGOI, L. Arranjo de plantas em milho: análise do estado da arte. Ciência Rural, v.31, p.1075-1084, 2001.

ARIAS, E. R. A. Adaptabilidade e estabilidade de cultivares de milho no Estado do Mato Grosso do Sul e avanço genético obtido no período de 1986/87 a 1993/94. 1996. 118f. Tese (Doutorado) - Escola Superior de Agricultura de Lavras, Lavras, 1996.

ASSUNÇÃO, P. S.; FRASSON, D. B.Avaliação do comportamento de híbridos de milho semeados em 3 épocas na região Parecis de Mato Grosso. Tangará da Serra, MT: P.A. Consultoria Agronômica, Pesquisa \& Agricultura de Precisão, 2014.
BARAVIERA, C. M. C.; CANEPELLE, C. DOURADO, L. G. A.; AGUERO, N. F. Avaliação de propriedades físicas de grãos de híbridos de milho. Enciclopédia Biosfera, Centro Científico Conhecer, v.10, n.19, p. 291-297, 2014.

CARDOSO, M. J.; CARVALHO, H. W. L.; ROCHA, L. M. P.; PACHECO, C. A. P.;

GUIMARAES, P. E. O. Adaptabilidade e estabilidade de híbridos convencionais e transgênicos. In: Congresso Nacional de Milho e Sorgo, Salvador. Anais... Salvador: ABMS, 2014.

COMPANHIA NACIONAL DE ABASTECIMENTO - CONAB. Acompanhamento da safra brasileira de grãos, 15/16. Brasília, 2016. 12p.

CRUZ, J. C. (Ed.). Cultivo do milho. 6.ed. Sete Lagoas: Embrapa Milho e Sorgo, 2010. (Embrapa Milho e Sorgo. Sistema de produção, 1). Disponível em: <http://www.cnpms.embrapa.br/ publicacoes/milho_6_ed/index.htm>. Acesso em: 19 abr. 2017.

EMPRESA BRASILEIRA DE PESQUISA AGROPECUÁRIA - EMBRAPA. Sistema de Produção: Cultivo de Milho. Sete Lagoas, 2011. 16p.

FREITAS, R.S.; DUARTE, A. P.; LEÃO, P. C. L.; KASAI, F.; CAZENTINI-FILHO, G.; TICELII, M.; MINGOTTE, F. L. C.; PESSINATTI, F. A.; FORNASIERI FILHO, D.; BORGES, W. L. B.; VITOR, L. G.; OLIVEIRA, A. L.; PONTE, S. S.Produtividade de grãos em cultivares de milho transgênicas na região norte/oeste do estado de São Paulo 
em 2011/12 e 2012/13. São Paulo: In: ENCONTRO TÉCNICO SOBRE AS

CULTURAS DA SOJA E DO MILHO NO NOROESTE PAULISTA, 1. 2013, São Paulo. Anais... São Paulo: USP, 2013.

GONÇALVES, D. A.; ALVES, R.; SILVIO JUNIOR, B. Sistema agroflorestal com paricá (Schizolobium amazonicum Huber ex. Ducke), cupuaçu (Theobroma grandiflorum (Willd. Ex Spreng.) Schum) e banana (Musa spp.), 50 ed. Belém: Embrapa Amazônia Oriental, 2008.

HANASHIRO, R. K.; MINGOTTE, F. L. C.; FORNASIERI FILHO, D. Desempenho fenológico, morfológico e agronômico de cultivares de milho em JaboticabalSP. Científica, Jaboticabal, v.41, n.2, p.226-234, 2013.

LORINI, I. Qualidade na armazenagem de grãos: vedação de armazéns e o expurgo dos grãos. Grãos Brasil, Maringá, PR, n.20, p.19-20, 2005.

MARCOS FILHO, J. Fisiologia de sementes de plantas cultivadas. Piracicaba. FEALQ, 2005. 495 p.

MINISTÉRIO DA AGRICULTURA PECUÁRIA E ABASTECIMENTO MAPA. Instrução Normativa N60, de 22 de dezembro de 2011. Lex: instrução normativa para regulamentação do milho, Brasília. dez. 2011.

NASCIMENTO, E. S.; GILO, E. G.; TORRES, F. E.; SILVA JUNIOR, C. A.; OLIVEIRA, L. V. A.; LOURENÇÃO, A. S. Resposta de híbridos de milho a diferentes espaçamentos entre linhas. Nucleus, Ituveraba, v. 9, n. 2, p. 131-140, 2011.

RIBEIRO, P. H. E.; RAMALHO, M. A. P.; FERREIRA, D. F. Adaptabilidade e estabilidade de cultivares de milho avaliadas em diferentes condições ambientais do Estado de Minas Gerais. In: REUNIÓN LATINOAMERICANA DEL MAIZ, 280., 2000, Sete Lagoas, Anais... Sete Lagoas: CIMMYT, 2000. p. 251260.

SANGOI, L.; GRACIETTI, M. A.; RAMPAZZO, C.; BIANCHET, P. Response of Brazilian maize hybrids from different eras to changes in plant density. Field Crops Research, v.79, p.39-51, 2002.

SILVA, G. C.; OLIVEIRA, F. J.; ANUNCIAÇÃO FILHO, C. J.; SIMÕES NETO, D.; MELO, LUIZ J. O. T. Divergência genética entre genótipos de cana de açúcar. Revista Brasileira de Ciências Agrárias. v.6, p. 52-58. 2011.

SIMONI, F.; COSTA-GEROLINETO, R. S.; FOGAÇA, C. A.; GEROLINETO, E.; Sementes de Sorghum bicolor L. Gramineae, submetidas ao estresse hídrico simulado com PEG (6000). Revista de Biologia e Ciência da Terra, Paraíba, v. 11, n. 1, p. 188-192, 2011.

SOUZA, L. C. D.; CARVALHO, M. A. C.; BRAGA, L. F.; SOUSA, M. P. et al. Qualidade fisiológica de sementes de arroz da região de Matupá - MT. Revista de Ciências Agro-Ambientais, Alta Floresta, v.3, p.110-116, 2005. 
STEFANELLO, J.; BACHI, L. M. A.; GAVASSONI, W. L.; HIRATA, L. M.; PONTIM, B. C. A. Incidência de fungos em grãos de milho em função de diferentes épocas de aplicação foliar de fungicida. Pesquisa Agropecuária Tropical, Goiânia, v. 42, n. 4, p. 476-481, out./dez. 2012.

SZCESNY, L. S. Densidade populacional de híbridos de milho em diferentes épocas de semeadura na região de Guarapuava - PR. 2015. 71f. Dissertação (Mestrado em Agronomia)

Universidade Estadual do CentroOeste, Guarapuava, 2015. 